\title{
Numerical study of scour depth effect on wave- induced seabed response and liquefaction around a pipeline
}

\author{
Hui Li, Shuqing Wang, Xuguang Chen, Cun Hu \& Jinzhong Liu
}

To cite this article: Hui Li, Shuqing Wang, Xuguang Chen, Cun Hu \& Jinzhong Liu (2019):

Numerical study of scour depth effect on wave-induced seabed response and liquefaction around a pipeline, Marine Georesources \& Geotechnology, DOI: 10.1080/1064119X.2019.1689588

To link to this article: https://doi.org/10.1080/1064119X.2019.1689588

曲 Published online: 14 Nov 2019.

Submit your article to this journal $₫$

Q View related articles $\sqsubset$

View Crossmark data $\complement$ 


\title{
Numerical study of scour depth effect on wave-induced seabed response and liquefaction around a pipeline
}

\author{
Hui Li ${ }^{a}$, Shuqing Wang ${ }^{a}$, Xuguang Chen ${ }^{a}, \mathrm{Cun} \mathrm{Hu}^{\mathrm{b}}$ and Jinzhong Liu ${ }^{\mathrm{c}}$ \\ ${ }^{a}$ Shandong Provincial Key Laboratory of Ocean Engineering, Ocean University of China, Qingdao, China; ${ }^{\mathrm{b}}$ Institute of Mechanics, Chinese \\ Academy of Sciences, Beijing, China; 'Key Laboratory of Ministry of Education for Geomechanics and Embankment Engineering, Hohai \\ University, Nanjing, China
}

\begin{abstract}
Wave-induced liquefaction depth is a key factor in providing the safe design of submarine pipelines. However, existing numerical studies simplify the seabed as a flat foundation and ignore the effect of scour depth on wave-induced seabed response and liquefaction depth. The effects of scour depth on wave-induced seabed response and liquefaction depth around a submarine pipeline are investigated, and a three-dimensional hybrid model combining Reynolds-averaged NavierStokes (RANS) equations with Biot's poroelastic theory for wave propagation and anisotropic seabed is proposed in this study. Numerical results indicate that local scour leads to the redistribution of the initial effective stress within the seabed around the pipeline. With increasing scour depths, the maximum liquefaction depth beneath the pipeline simultaneously decreases. When the scour depth reaches a certain depth, the seabed seems to no longer liquefy. Parametric studies indicate that the liquefaction depth increases by either decreasing the saturation degree or increasing the wave height. Under anisotropic seabed conditions, a nonlinear relationship exists between the maximum liquefaction depth of the seabed and the seabed permeability.
\end{abstract}

\section{ARTICLE HISTORY}

Received 30 June 2019

Accepted 31 October 2019

\section{KEYWORDS}

Pipeline; liquefaction depth; scour depth; pore pressure response; aniso-

tropic seabed

\section{Introduction}

Submarine pipelines are among the most common marine engineering structures and are widely used to transport oil and gas in the offshore industry. When a static submarine pipeline is laid upon an erodible noncohesive porous seabed and subjected to ocean waves or currents, there is every probability that seabed liquefaction and local scour occur around the pipeline due to hydrodynamic loadings. When the liquefaction depth becomes larger, the pipeline starts to sag. The pipeline is susceptible to wave-induced instability and large bending induced leakage. Hence, the evaluation of the wave-induced seabed response and maximum liquefaction depth around a pipeline has gained much attention from submarine pipeline designers and researchers (Veritas 2010; Sumer and Mutlu 2014; Gao, Wang, and Li 2016).

When waves propagate over a porous seabed, the soil skeleton is subjected to wave-induced hydrodynamic pressure. Once the upward seepage force produced by pore pressure exceeds the effective self-weight of the overburdened soil, part of the seabed may be liquefied (Huang et al. 2015; Zhang, Huang, and Bao 2016; Zhang et al. 2019), thereby threatening the stability of submarine pipelines. Based on Biot's theory of poroelasticity, Jeng, Rahman, and Lee (1999) developed a twodimensional FEM numerical model to study the wave-induced seabed response. Zhou, Zhang, and Yan (2014) studied the effect of anisotropic seabed behavior on the wave-induced pore pressure response around a submarine pipeline, but it was limited to two-dimensional cases. Liu et al. (2015) performed a physical test to explore the effects of seabed characteristics on the wave-induced pore pressure response. Their results indicated that the influences of seabed characteristics on the seabed response were considerable. Duan, Jeng, et al. (2017) proposed a three-dimensional (3D) isotropic finite element model to examine the effect of wave characteristics on wave-induced transient liquefaction around a partially buried pipeline. The numerical results suggested that the change in the turbulent flow field would affect the liquefaction depth. Li, Ong, and Tang (2018) analyzed the development of pore pressure within the seabed around a gravity-based foundation and argued that the influence of the initial effective stress on pore pressure responses was significant. In summary, these previous studies have shown that the turbulent flow field, soil properties and initial effective stress affect the liquefaction depth $\left(h_{l}\right)$ and the distribution of pore pressure.

Waves can create excess pore pressure within the seabed. It is also inevitable that local scour would take place below the pipeline due to the action of waves. However, most previous investigations ignored the effect of local scour on the waveinduced pore pressure response and liquefaction depth around a pipeline. Experimental results indicated that, under the action of waves or currents, the equilibrium stage of local scour was reached in a short time (Mao 1986; Sumer, Mao, 


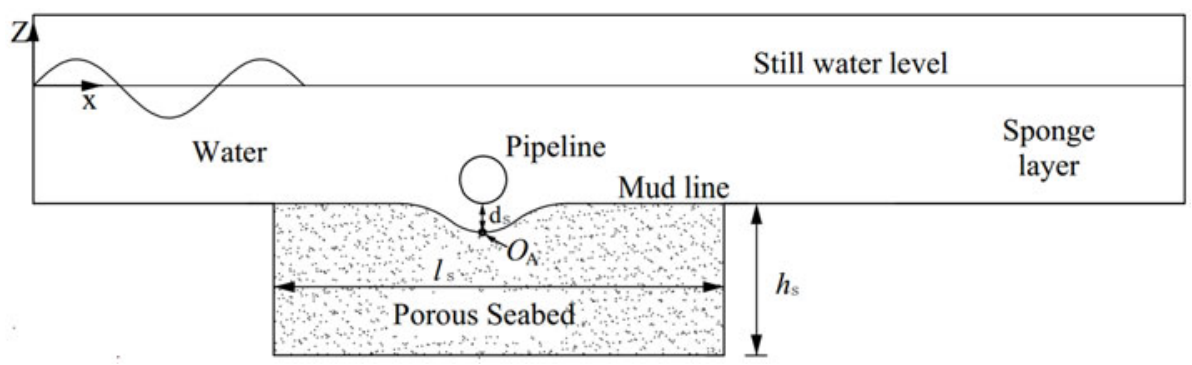

Figure 1. Definition sketch of the numerical model.

and Freds 1988; Sumer et al. 2001; Wu and Chiew 2012); then, sediment transport reached a dynamic equilibrium (Mattioli et al. 2012, 2013), but wave-induced pore pressure response and transient liquefaction occurred throughout the entire lifecycle of submarine pipelines (Jeng 2012). The effect of equilibrium scour depth on wave-induced pore pressure response has not been clear, making it essential to assess the influence of equilibrium scour depth on wave-induced pore pressure response and liquefaction depth (Qi and Gao 2014). Previous studies showed that the equilibrium scour depths were usually $0.5 \sim 1.3$ times the pipeline diameter (D) (Sumer and Fredsøe 2002; Gao et al. 2006; Fredsøe 2016). For practical purposes, Fredsøe, Sumer, and Arnskov (1992) claimed that the equilibrium scour depths were $0.5 \sim 0.6 \mathrm{D}$ in the pipeline safety design. The influence of local scour on pore pressure responses is mainly reflected in two aspects. On the one hand, local scour will affect the turbulent flow field around the pipeline (Gonzalez-Juez et al. 2010; Jung, Yoon, and Oceaneng 2016). Wave pressure acting on the seabed surface will be changed for various scour depths, thereby further affecting the distribution of the pore pressure within the seabed. On the other hand, local scour will also lead to significant perturbations of the initial stress field within the seabed owing to missing soil around the pipeline. Most previous investigations have not considered the stress state after the equilibrium of scour is reached as the initial condition by assuming that no scour would occur around the pipeline. This assumption makes the predictions of the liquefaction depth of the seabed foundation doubtable.

The primary aim of this study is to investigate the waveinduced oscillatory seabed response and maximum liquefaction depth $\left(h_{l}\right)$ around a pipeline with different equilibrium scour depths $\left(S_{e q}\right)$. The stress release caused by scour is considered. To meet this objective, a 3D integrated model is proposed, in which Reynolds-averaged Navier-Stokes equations with the $\kappa-\varepsilon$ turbulent model are adopted to describe the nonlinear waves and an anisotropic seabed model is used to simulate the dynamic response of the seabed. The interaction between the fluid domain and seabed domain is implemented by interface coupling using a unifying framework of the finite volume method (FVM). Then, a series of soil properties and wave properties studies are carried out to elucidate the effects of anisotropic soil on the seabed response and maximum liquefaction depth $\left(h_{l}\right)$.

\section{Numerical model}

As shown in Figure 1, the entire computational domain is established in a typical Cartesian coordinate system. The coupled integrated numerical model contains two submodels: the wave model is adopted to simulate the wave motion, and the anisotropic seabed model is adopted to capture the oscillatory soil response. In this figure, $L$ is the wavelength, $h_{s}$ is the seabed thickness, $l_{s}$ is the seabed length, and $O_{A}$ is the observation point. The length of the inlet relaxation zone is $L$. To diminish the wave reflection from the outflow boundary, the length of the outlet relaxation zone is set to $2 L$ (Jacobsen, Fuhrman, and Fredsøe 2012).

\subsection{Wave model}

The governing equations for simulating incompressible Newtonian fluid motion are based on mass and momentum conservation equations. The incompressible fluid motion due to waves can be described by the Reynolds-averaged Navier-Stokes equations.

$$
\begin{gathered}
\nabla \boldsymbol{u}=0 \\
\frac{\partial \boldsymbol{u}}{\partial t}+\boldsymbol{u}(\nabla \boldsymbol{u})=-\frac{1}{\rho} \nabla p_{f}+\mathbf{g}+\frac{1}{\rho} \nabla\left[\boldsymbol{\mu}\left(\nabla \boldsymbol{u}+(\nabla \boldsymbol{u})^{T}\right)+\tau\right]
\end{gathered}
$$

where $\boldsymbol{u}$ denotes the flow velocity; $\rho$ represents fluid density; $t$ is time; $p_{f}$ is the fluid pressure; $\mathbf{g}$ represents the gravitational acceleration vector and $\tau$ is the Reynolds stress tensor defined as:

$$
\tau=2 \mu_{t} \mathbf{S}-\frac{2}{3} \rho \boldsymbol{\delta} k
$$

where the mean strain rate tensor $\mathbf{S}=1 / 2\left(\nabla \boldsymbol{u}+(\nabla \boldsymbol{u})^{T}\right)$; $\mu$ denotes the dynamic viscosity; $\kappa$ is the turbulence kinetic energy (TKE) and $\boldsymbol{\delta}$ represents the Kronecker delta.

The $\kappa-\varepsilon$ turbulence model (Wilcox 1998) adopted in the study can be expressed as:

$$
\begin{gathered}
\frac{\partial \kappa}{\partial t}+\boldsymbol{u}(\nabla \kappa)=\nabla\left[\left(\mu+\frac{\mu_{t}}{\sigma_{k}}\right) \nabla \kappa\right]+P_{k}-\rho \varepsilon \\
\frac{\partial \varepsilon}{\partial t}+\boldsymbol{u}(\nabla \varepsilon)=\nabla\left[\left(\mu+\frac{\mu_{t}}{\sigma_{\varepsilon}}\right) \nabla \varepsilon\right]+C_{1 \varepsilon} \frac{\varepsilon}{\kappa} P_{k}-C_{2 \varepsilon} \rho \frac{\varepsilon^{2}}{\kappa}
\end{gathered}
$$

where $\quad P_{k}=\mu_{t}\left[\nabla \boldsymbol{u}:\left(\nabla \boldsymbol{u}+(\nabla \boldsymbol{u})^{T}\right)\right] \quad$ and $\quad \mu_{t}=\rho C_{\mu} \kappa^{2} / \varepsilon$ denotes the turbulent viscosity. The constant coefficients are taken $\quad$ as $\quad C_{\mu}=0.09, \quad \sigma_{k}=1.0, \quad \sigma_{\varepsilon}=1.3, \quad C_{1 \varepsilon}=1.44$ and $C_{2 \varepsilon}=1.92$, as suggested by Wilcox (1998). 


\subsection{Anisotropic Biot's porous soil model}

Biot's poroelastic theory is generally acceptable to describe the mechanical behavior of the compressible pore fluid flowing in a porous medium, in which the soil is considered as an anisotropic and heterogeneous medium. Based on Biot's poro-elastic theory, the Quasi-static momentum balance equation can be expressed as follows:

$$
\nabla\left[\boldsymbol{C}: \frac{1}{2}\left(\nabla \mathbf{U}+(\nabla \mathbf{U})^{T}\right)\right]-\nabla p=0
$$

where $C$ denotes the elastic stiffness tensor, $p$ represents the pore pressure and $\mathbf{U}$ is the soil displacement vector. The matrix of the orthotropic elastic stress-strain relation can be described as follows:

$$
\sigma^{\prime}=\left(\begin{array}{c}
\sigma_{x}^{\prime} \\
\sigma_{y}^{\prime} \\
\sigma_{z}^{\prime} \\
\sigma_{x y}^{\prime} \\
\sigma_{y z} \\
\sigma_{x z}
\end{array}\right)=\left[\begin{array}{cccccc}
A_{11} & A_{12} & A_{31} & 0 & 0 & 0 \\
A_{12} & A_{22} & A_{23} & 0 & 0 & 0 \\
A_{31} & A_{23} & A_{33} & 0 & 0 & 0 \\
0 & 0 & 0 & A_{44} & 0 & 0 \\
0 & 0 & 0 & 0 & A_{55} & 0 \\
0 & 0 & 0 & 0 & 0 & A_{66}
\end{array}\right]\left(\begin{array}{c}
\varepsilon_{x x} \\
\varepsilon_{y y} \\
\varepsilon_{z z} \\
\varepsilon_{x y} \\
\varepsilon_{y z} \\
\varepsilon_{x z}
\end{array}\right)=\boldsymbol{C} \cdot \varepsilon
$$

where $\sigma^{\prime}$ denotes the effective stress tensor and $\varepsilon$ is the soil strain. According to the research of Demirdzic, Horman, and Martinovic (2000), the nine nonzero independent coefficients $A_{i j}$ are calculated from the shear modulus $G_{i}$, Poisson's ratio $\nu_{i j}$ and Young's modulus $E_{i}$ as follows:

$$
\begin{gathered}
A_{11}=\frac{1-\nu_{y z} \nu_{z y}}{J E_{y} E_{x}} A_{22}=\frac{1-\nu_{x z} \nu_{z x}}{J E_{z} E_{x}} A_{33}=\frac{1-\nu_{y x} \nu_{x y}}{J E_{y} E_{x}} \\
A_{12}=\frac{\nu_{x y}+\nu_{z y} \nu_{x z}}{J E_{x} E_{z}} A_{23}=\frac{\nu_{y z}+\nu_{x y} \nu_{x z}}{J E_{x} E_{y}} A_{31}=\frac{\nu_{x z}+\nu_{x y} \nu_{y z}}{J E_{y} E_{z}} \\
A_{44}=2 G_{x y} \\
A_{55}=2 G_{z y} \\
A_{66}=2 G_{z x}
\end{gathered}
$$

in which

$$
J=\frac{1-\nu_{x y} \nu_{y x}-\nu_{y z} \nu_{z y}-\nu_{x z} \nu_{z x}-2 \nu_{x y} \nu_{y z} \nu_{x z}}{E_{x} E_{y} E_{z}}
$$

The mass balance equation of the pore fluid can be defined as follows:

$$
\frac{n_{s}}{K^{\prime}} \frac{\partial p}{\partial t}-\frac{1}{\gamma_{w}} \nabla \cdot(\mathbf{k} \cdot \nabla p)+\frac{\partial}{\partial t}(\nabla \cdot \mathbf{U})=0
$$

where $n_{s}$ denotes the soil porosity, $\gamma_{w}$ is the unit weight of the pore water and $\mathbf{k}$ represents the diagonal permeability tensor with values of $K_{x}, K_{y}$ and $K_{z}$. For unsaturated soil, the combined flow of water and air in the pores is simply considered as a single fluid, with the approximated bulk modulus:

$$
\frac{1}{K^{\prime}}=\frac{1}{K_{w}}+\frac{1-S_{r}}{P_{a}}
$$

where $K_{w}$ denotes the true bulk modulus of pure water, taken as $2 \times 10^{9} \mathrm{~N} / \mathrm{m}^{2}$, according to Yamamoto et al. (1978); $S_{r}$ represents the degree of saturation and $P_{a}$ is the absolute hydrostatic pressure.

\subsection{Boundary conditions}

The entire numerical domain covers the range $\mathrm{x}=0$ to $\mathrm{x}=$ $414 \mathrm{~m}$ in the horizontal direction, $\mathrm{y}=0$ to $\mathrm{y}=132 \mathrm{~m}$ and $\mathrm{z}=-16 \mathrm{~m}$ to $\mathrm{z}=4 \mathrm{~m}$ in the vertical direction.

In the flow model, the fifth-order Stokes wave theory is adopted for wave modelling. An active absorption boundary similar to the work of Higuera, Lara, and Losada (2013) is located in the outlet to ensure no wave reflection. At the pipeline and seabed floor interface, a no-slip boundary is adopted. At the free water surface, the pressure is equal to the atmospheric pressure.

In the seabed domain, the pore pressure equals the hydrodynamic pressure on the seabed extracted from the flow model. The shear stresses and effective normal stresses vanish at the wave-seabed interface. At the lateral boundaries and bottom of the soil domain, the normal pore pressure gradient vanishes in accordance with the impermeability condition.

1. Wave-seabed interface: $p_{b}=p_{w}$, where $p_{w}$ is the hydrodynamic pressure extracted from the flow model.

2. Lateral boundary: $\partial p_{s} / \partial x=0$ and $\partial p_{s} / \partial y=0$, where $p_{s}$ is the pore pressure amplitude at a depth of the seabed.

3. Bottom boundary: $\partial p_{s} / \partial z=0$.

\subsection{Integration process between the wave and seabed models}

In the present model, the wave model and soil model are both developed utilizing the FVM within the framework of OpenFOAM. To integrate the seabed model and the wave model together at the interface, a matching mesh system is adopted, which can transfer the dynamic wave pressure via the common notes, and avoid generating linear interpolation for every face center. Therefore, the present integrated model is capable of simulating the wave-seabed interaction more accurately (Lin et al. 2017).

\section{Validation}

To ensure the validity of the simulations, we validate the integrated numerical model against the available experimental results in the published literature.

The first validation case for the distribution of the pore pressure along the periphery of the pipeline is the laboratory experiments carried out by Turcotte, Kulhawy, and Liu (1984) in a wave tank with water depth $\mathrm{H}=0.533 \mathrm{~m}$. In the experiment, the diameter of the pipeline was $0.168 \mathrm{~m}$ with a burial depth of $0.107 \mathrm{~m}$. The comparison of the numerical results and experimental data of the pore pressure along the periphery of the pipeline are plotted in Figure 2.

Figure 2 shows that at the two wave parameters, the numerical results of the pore pressure reach good agreement with the experimental data. This means that the model is sufficiently accurate to capture the distribution of the pore pressure along the periphery of the pipeline. 

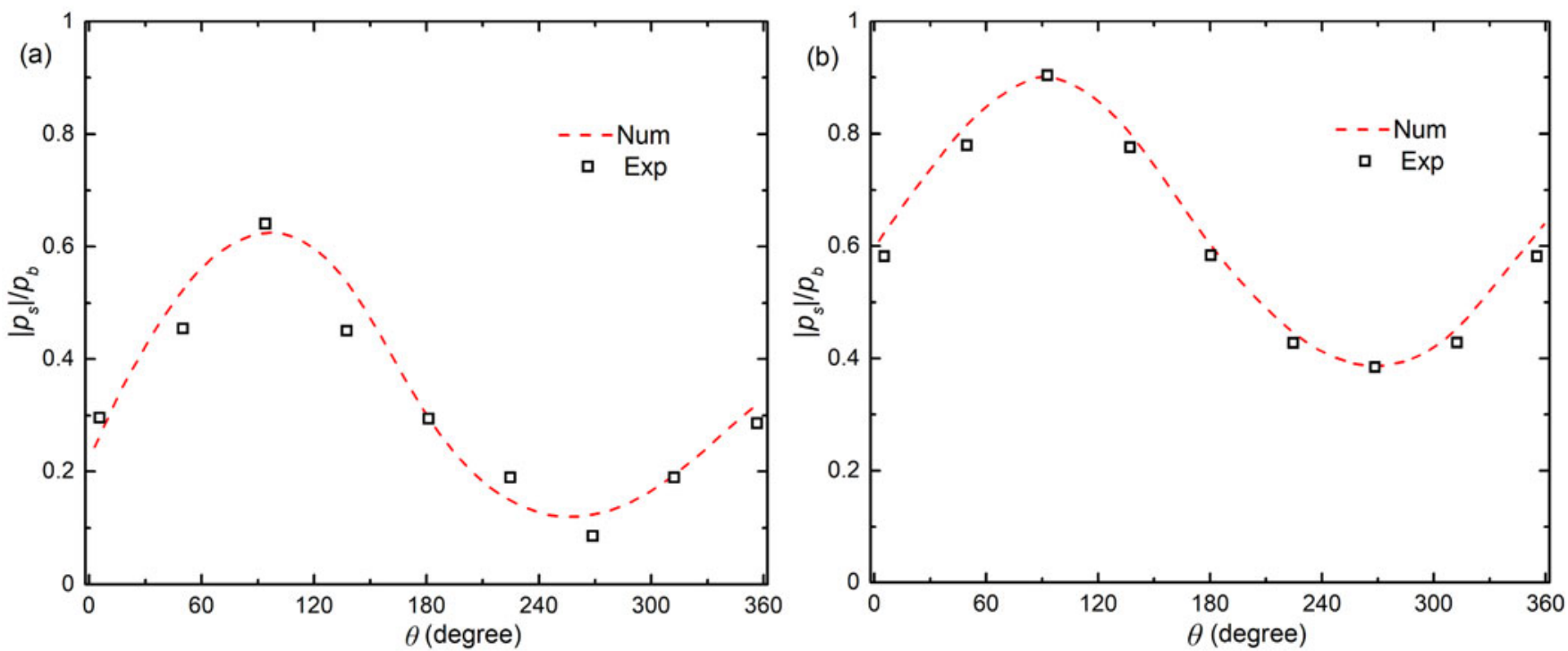

Figure 2. Validation of the pore pressure along the periphery of the pipeline between the integrated numerical model and the experimental data in Turcotte, Kulhawy, and Liu (1984): (a) $H=0.0524 \mathrm{~m}$ and $T=0.9 \mathrm{~s}$; (b) $H=0.143 \mathrm{~m}$ and $T=1.75 \mathrm{~s}$.

Table 1. Parameters used in the second validation.

\begin{tabular}{|c|c|c|c|}
\hline \multicolumn{4}{|l|}{ Wave characteristics } \\
\hline \\
\hline \\
\hline \multirow{2}{*}{\multicolumn{4}{|c|}{$1.27 \times 10^{7} \mathrm{~Pa}$}} \\
\hline & & & \\
\hline \multirow{2}{*}{$\begin{array}{l}\text { Degree of saturation }\left(S_{r}\right) \\
\text { Permeability }\left(k_{s}\right)\end{array}$} & 0.975 (dense) & \multirow{2}{*}{\multicolumn{2}{|c|}{$\begin{array}{l}0.955 \text { (loose) } \\
4 \times 10^{-4} \mathrm{~m} / \mathrm{s} \text { (loose) }\end{array}$}} \\
\hline & $1 \times 10^{-4} \mathrm{~m} / \mathrm{s}$ (dense) & & \\
\hline
\end{tabular}

In the second validation, the seabed model without the coupling wave model is validated with an experimental test by Tsui et al. (1983) in a wave tank $(24.7 \mathrm{~m} \times 0.6 \mathrm{~m})$. In the experiment, the soil test site $(1.7 \mathrm{~m} \times 0.6 \mathrm{~m})$ was located $13 \mathrm{~m}$ from the wave generator. Pore pressure transducers were installed along the vertical axis of the test site. The parameters adopted in the second validation are listed in Table 1.

Figure 3 demonstrates the distribution of the normalized pore pressure amplitude $\left(p_{s} / p_{b}\right)$ along with the seabed thickness $(z / h)$. In Figure 3 , the pore pressures obtained by numerical simulations are generally close to those from laboratory experiments. It is worth noting that a slight deviation in the pore pressure within the seabed exists between the numerical simulations and the experimental results, mostly due to the change in the soil parameters during the experiment.

In the third validation, the predicted wave-induced pore pressures are compared with the laboratory measurements of Liu et al. (2015). In their experiments, pore pressure transducers installed in a sandy deposit measured the pore pressure evolution in the sandy sediment at different depths. The parameters adopted in the third validation are listed in Table 2. The simulated results of the pore pressure within the seabed in a time series are shown in Figure 4.

Figure $4(\mathrm{a}, \mathrm{b})$ shows the verification of the time series of the pore pressures at two pore pressure gauges located $6.7 \mathrm{~cm}$ and $26.7 \mathrm{~cm}$ from the seabed surface with the

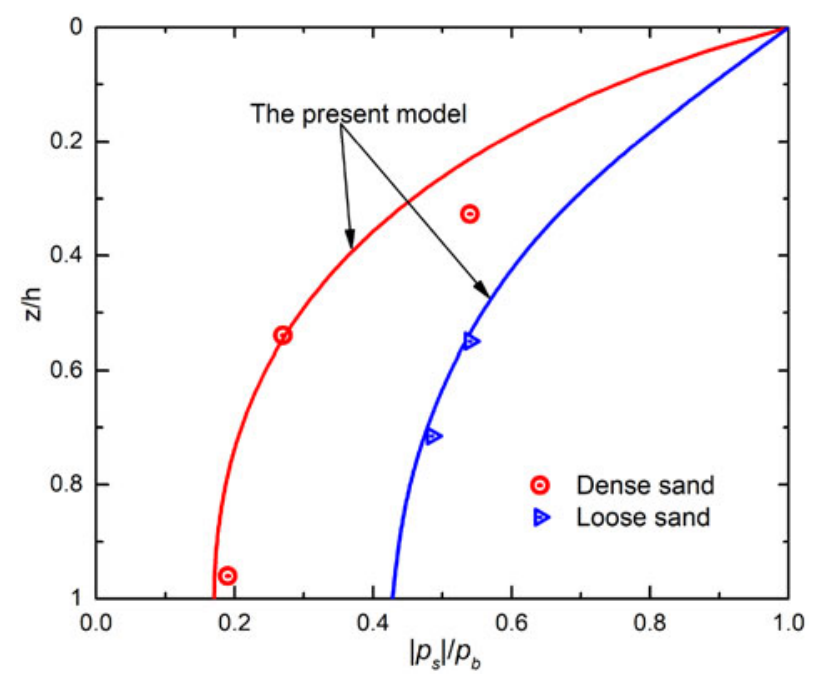

Figure 3. Validation of the vertical distribution of the normalized pore pressure amplitude between the integrated numerical model and the experimental data in Tsui et al. (1983).

experimental data. Figure 4 shows that the predicted pore pressures agree well with the experimental data.

\section{Numerical results and discussion}

As previously mentioned, the main purpose of this paper is to investigate the effect of the scour depth on the waveinduced pore pressure response and maximum liquefaction depth around a submarine pipeline. First, the effect of the scour depth on the distributions of seabed initial effective stresses is presented. Second, the effect of the scour depth on the wave-induced pore pressure and maximum liquefaction depth is studied. Finally, the effects of the wave characteristics and seabed characteristics on the wave-induced pore pressure response and maximum liquefaction depth are investigated. We adopt the equilibrium profile from the experiments by Sumer and Fredsøe (1990) and the ratio of 
the equilibrium scour depth $\left(S_{e q}\right)$ to the pipeline diameter $(D)$ in the range of $0.25 \leq S_{e q} / D \leq 1.25$. Because the liquefaction of the seabed usually occurs in a shallow domain, the analysis domain $h$ is mainly three meters below the bottom of the scour hole $(h=3 \mathrm{~m})$, i.e., three times the pipeline diameter $(h=3 \mathrm{D})$. That is, the analysis domain starts from the reference point $O_{\mathrm{A}}$, as indicated in Figure 5. The basic properties for the wave and soil derived from Duan, Liao, et al., (2017) and Li, Ong, and Tang (2018) are tabulated in Table 3 unless otherwise specified.

\subsection{Initial consolidation and stress release}

In natural marine environments, the initial stress state significantly affects the estimation of the wave-induced liquefaction depth within the seabed (Jeng 2012). The liquefaction criteria proposed by Jeng (1997) are widely accepted and can be expressed as follows:

$$
\sigma_{0}^{\prime}+u_{e}<0
$$

where $\sigma_{0}^{\prime}$ is the initial effective stress, and $u_{e}=p_{s}-p_{b}$ denotes the excess pore water pressure. For a flat seabed, the initial effective stress $\sigma_{0}^{\prime}$ is normally defined as follows:

$$
\sigma_{0}^{\prime}=\left(1+2 K_{0}\right) \gamma^{\prime} z / 3
$$

where $\gamma^{\prime}$ is the buoyant unit weight and $K_{0}$ denotes the lateral pressure coefficient. However, this definition may not be appropriate in the present study due to the complicated configuration of the scour hole. In practice, local scour leads

\begin{tabular}{|c|c|c|c|}
\hline \multicolumn{4}{|l|}{ Wave characteristics } \\
\hline Wave height $\left(h_{w}\right)$ & $3.5 \mathrm{~m}$ & Wave period $(T)$ & $9 \mathrm{~s}$ \\
\hline Water depth $(H)$ & $5.2 \mathrm{~m}$ & Wavelength $\left(I_{w}\right)$ & $61.5 \mathrm{~m}$ \\
\hline \multicolumn{4}{|l|}{ Seabed characteristics } \\
\hline Shear modulus $(G)$ & $1.27 \times 10^{7} \mathrm{~Pa}$ & Porosity $\left(n_{s}\right)$ & 0.425 \\
\hline Poisson's ratio $\left(\mu_{s}\right)$ & 0.3 & Seabed thickness (h) & $1.8 \mathrm{~m}$ \\
\hline Degree of saturation $\left(S_{r}\right)$ & 0.951 & Permeability $\left(k_{s}\right)$ & $1.8 \times 10^{-4} \mathrm{~m} / \mathrm{s}$ \\
\hline
\end{tabular}

Table 2. Parameters adopted in the third validation. to noticeable perturbations of the initial stress field in the soil surrounding the scour hole. The changes in the initial stress field before scour and after scour are shown in Figure 5. After the local scour hole is formed, the original loading balance is broken down, and the initial stress field is redistributed. Stress release occurs in the soil surrounding the scour hole. Due to the influence of the overburden pressure and friction between the sand particles, the release of stress decreases with increasing seabed depth.

The effective stress proposed by Zen and Yamazaki (1990) will be applied in this study. This can be written as follows:

$$
\sigma_{0}^{\prime}=\frac{1}{\sqrt{3}} \sqrt{\left(\sigma_{x x}^{\prime}\right)^{2}+\left(\sigma_{y y}^{\prime}\right)^{2}+\left(\sigma_{z z}^{\prime}\right)^{2}}
$$

where $\sigma_{x x}^{\prime}$ and $\sigma_{y y}^{\prime}$ are the initial horizontal effective stresses and $\sigma_{z z}^{\prime}$ is the initial vertical effective stress. Figure 6 shows the distribution of the initial effective stress within the

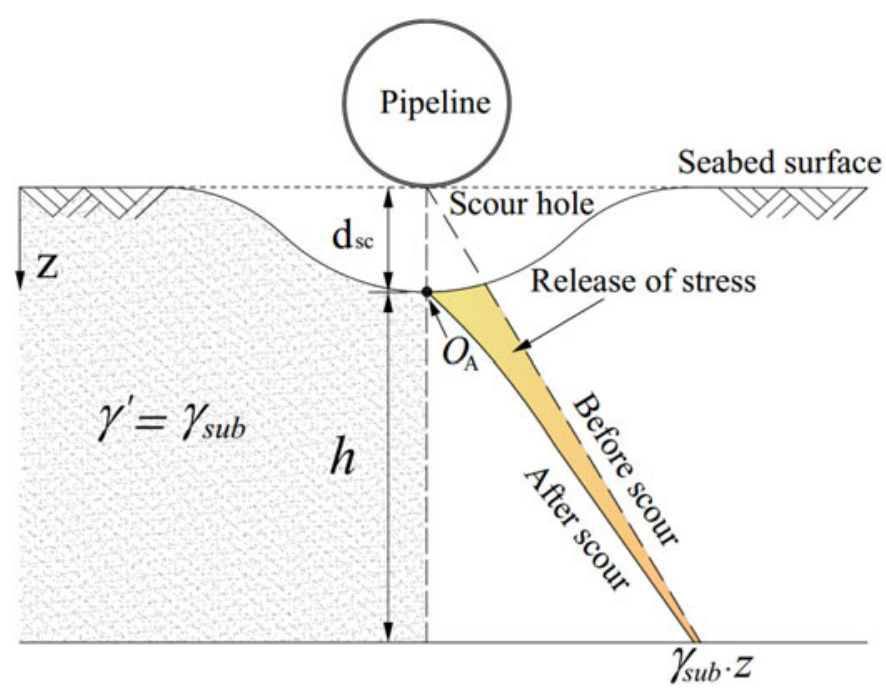

Figure 5. Schematic diagram of the contrast in vertical effective stress before and after scour.
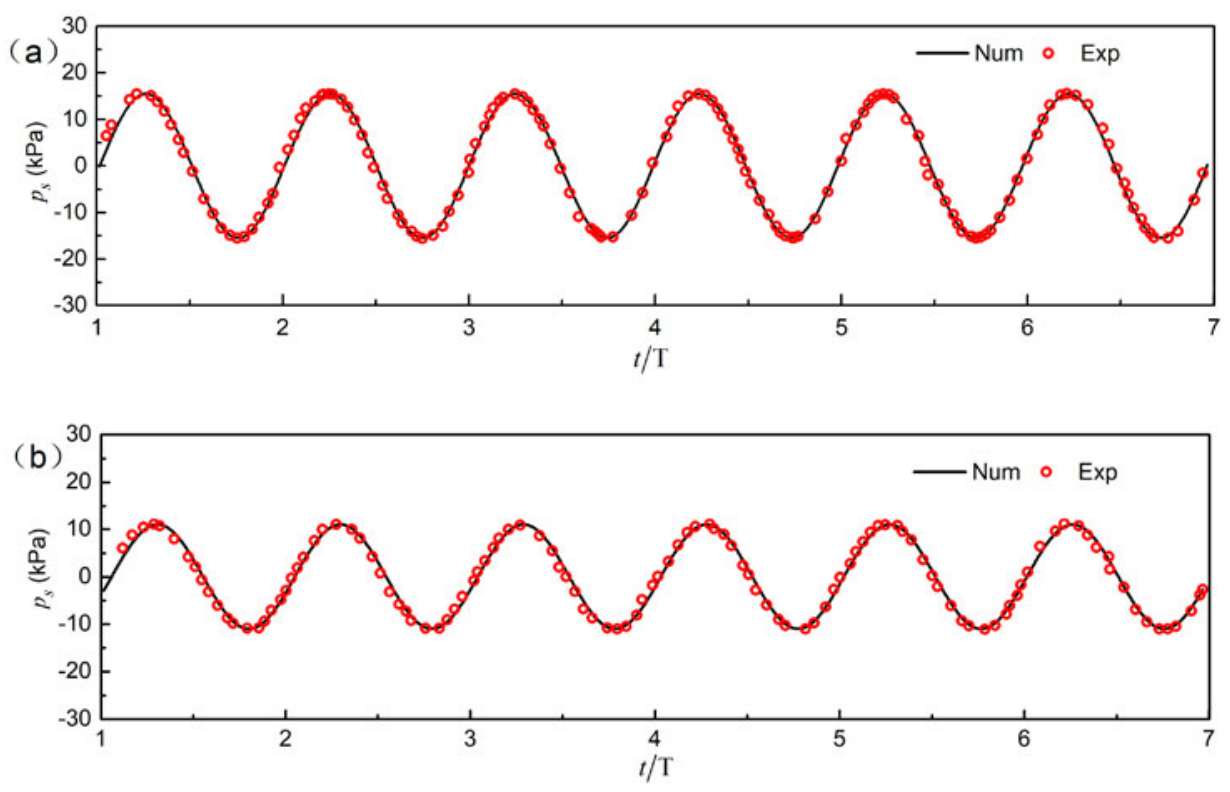

Figure 4. Validation of the pore pressure evolution against the experimental data of Liu et al. (2015). 
Table 3. Properties of the seabed adopted in the case studies.

\begin{tabular}{llll}
\hline $\begin{array}{l}\text { Wave characteristics } \\
\text { Wave height }\left(h_{w}\right)\end{array}$ & $3.4 \mathrm{~m}$ & $\begin{array}{l}\text { Wave period }(T) \\
\text { Wavelength }\left(I_{w}\right)\end{array}$ & $10 \mathrm{~s}$ \\
$\begin{array}{l}\text { Water depth }(H) \\
\text { Seabed characteristics }\end{array}$ & $10 \mathrm{~m}$ & & $92 \mathrm{~m}$ \\
Seabed thickness $\left(h_{s}\right)$ & $6 \mathrm{~m}$ & Seabed length $\left(I_{s}\right)$ & $132 \mathrm{~m}$ \\
Degree of saturation $\left(S_{r}\right)$ & 0.97 & Submerged density $\left(r_{\text {sub }}\right)$ & $10.62 \mathrm{KN} / \mathrm{m}^{3}$ \\
Permeability $\left(k_{s}\right)$ & $K_{x}=5 \times 10^{-3} \mathrm{~m} / \mathrm{s}$ & $K_{y}=5 \times 10^{-3} \mathrm{~m} / \mathrm{s}$ & $K_{z}=1.0 \times 10^{-4} \mathrm{~m} / \mathrm{s}$ \\
Young's modulus $\left(E_{s}\right)$ & $E_{x}=1.2 \times 10^{7} \mathrm{~N} / \mathrm{m}^{2}$ & $E_{y}=1.2 \times 10^{7} \mathrm{~N} / \mathrm{m}^{2}$ & $E_{z}=2 \times 10^{7} \mathrm{~N} / \mathrm{m}^{2}$ \\
Shear modulus $\left(G_{s}\right)$ & $G_{x y}=5 \times 10^{6} \mathrm{~N} / \mathrm{m}^{2}$ & $G_{y z}=1.2 \times 10^{7} \mathrm{~N} / \mathrm{m}^{2}$ & $G_{z x}=1.2 \times 10^{7} \mathrm{~N} / \mathrm{m}^{2}$ \\
Poisson's ratio $\left(\mu_{s}\right)$ & $\nu_{x y}=0.2$ & $\nu_{y z}=0.24$ & $\nu_{z x}=0.4$ \\
Porosity $\left(n_{s}\right)$ & 0.4 & & \\
$\begin{array}{l}\text { Pipeline parameters } \\
\text { Pipeline diameter }(D)\end{array}$ & $1 \mathrm{~m}$ & & \\
\hline
\end{tabular}

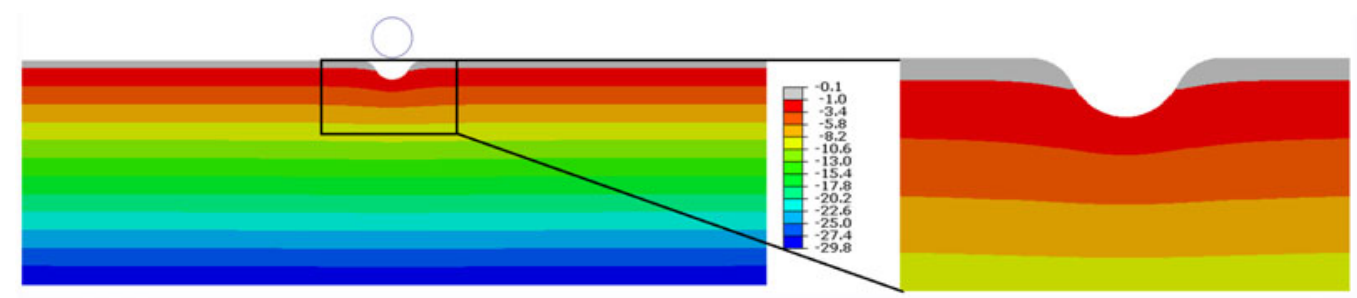

(a) The initial horizontal effective stress

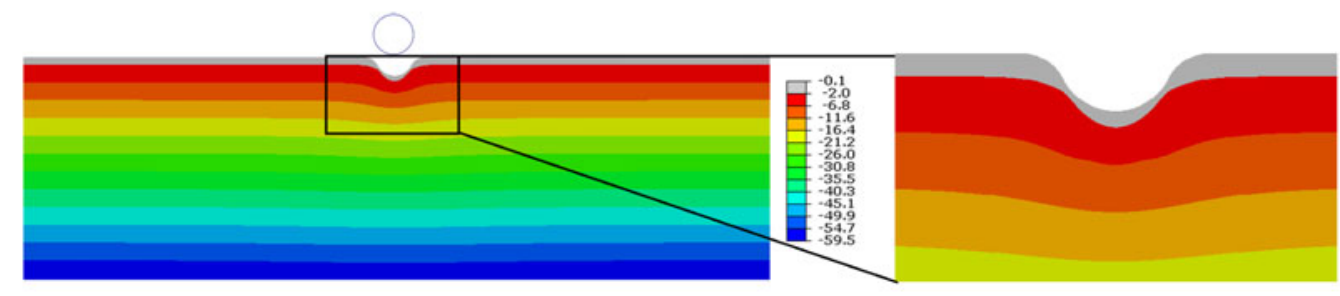

(b) The initial vertical effective stress

Figure 6. Contours of distribution of the initial effective stress with $S_{e q} / D=0.5$.

seabed after the local scour reaches equilibrium states with $S_{e q} / D=0.5$. In the region far away from the scour hole, the initial effective stress increases gradually from the seabed surface to the bottom, which comes from the self-weight of the seabed soil. Stress release occurs in the soil around the scour hole. In this region, the excess pore pressure can easily exceed the reduced effective stress, which would cause the seabed to liquefy. By comparing Figure $6(a, b)$ the stress release in the vertical direction is significantly greater than that in the horizontal direction.

Figure 7(a) shows the vertical effective stress along the vertical axis beneath the bottom of the scour hole $(h)$. The vertical effective stress is released completely in the upper zone of the seabed. This is because the scour will lead to missing soil around the pipeline, resulting in a free face at the bottom of the scour hole, and the soil will rebound, thus releasing stress. However, in the lower part of the seabed, due to the influence of the overburden soil pressure, the rebound of the soil decreases, and then the stress release gradually weakens. Figure 7 (b) shows the horizontal effective stress along the vertical axis through the center of the scour hole. It is shown that the scour depth has a slight effect on the distribution of the horizontal effective stress. This is because the horizontal deformation is smaller, resulting in a relatively small stress release.

\subsection{Effects of scour depth on the pore pressure response and liquefaction depth around a pipeline}

Figure 8 shows the time series of the wave pressure $\left(p_{b}\right)$ for various scour depths at point $O_{\mathrm{A}}$, as indicated in Figure 1. With the increase in scour depths, the wave pressure amplitude has a slight increase. The change in the wave pressure $\left(p_{b}\right)$ under wave crests is more significant than under wave troughs. When the equilibrium scour depth $\left(S_{e q}\right)$ varied from $0.25 D$ to $1.25 D$, the wave pressure amplitude $\left(\left|p_{b}\right|\right)$ increased by $18.64 \%$ under the wave crests and increased by $8.8 \%$ under the wave troughs. The change in the wave pressure $\left(p_{b}\right)$ indicates that the wave pressure acting on the seabed has a relatively slight increasing trend with the increase in scour depths.

Figure 9 shows the streamlines around a pipeline with different equilibrium scour depths $\left(S_{e q}\right)$ under wave troughs. When the scour depth $\left(S_{e q} / D=0.25\right)$ is small, the asymmetric and deflected flow wake behind the pipeline and the downstream separation bubble can be observed, as shown in Figure 9(a). As water jet flow is formed beneath the pipeline, the pressure difference between upstream and downstream of the scour hole leads to an increase in the seabed shear stress and accelerates the scour process. When the scour depth reaches $0.5 \mathrm{D}$, the downstream separation bubble 
disappears. The ability of the flow to scour the seabed is weakened.

Figure 10 demonstrates the distribution of the waveinduced pore pressure for various scour depths. As expected, the pore pressure peak appears near the seabed surface and decreases with depth. As the scour depth increases, the wave-induced pore pressure peak has a slight increase under the wave troughs. This is because the local scour disturbs
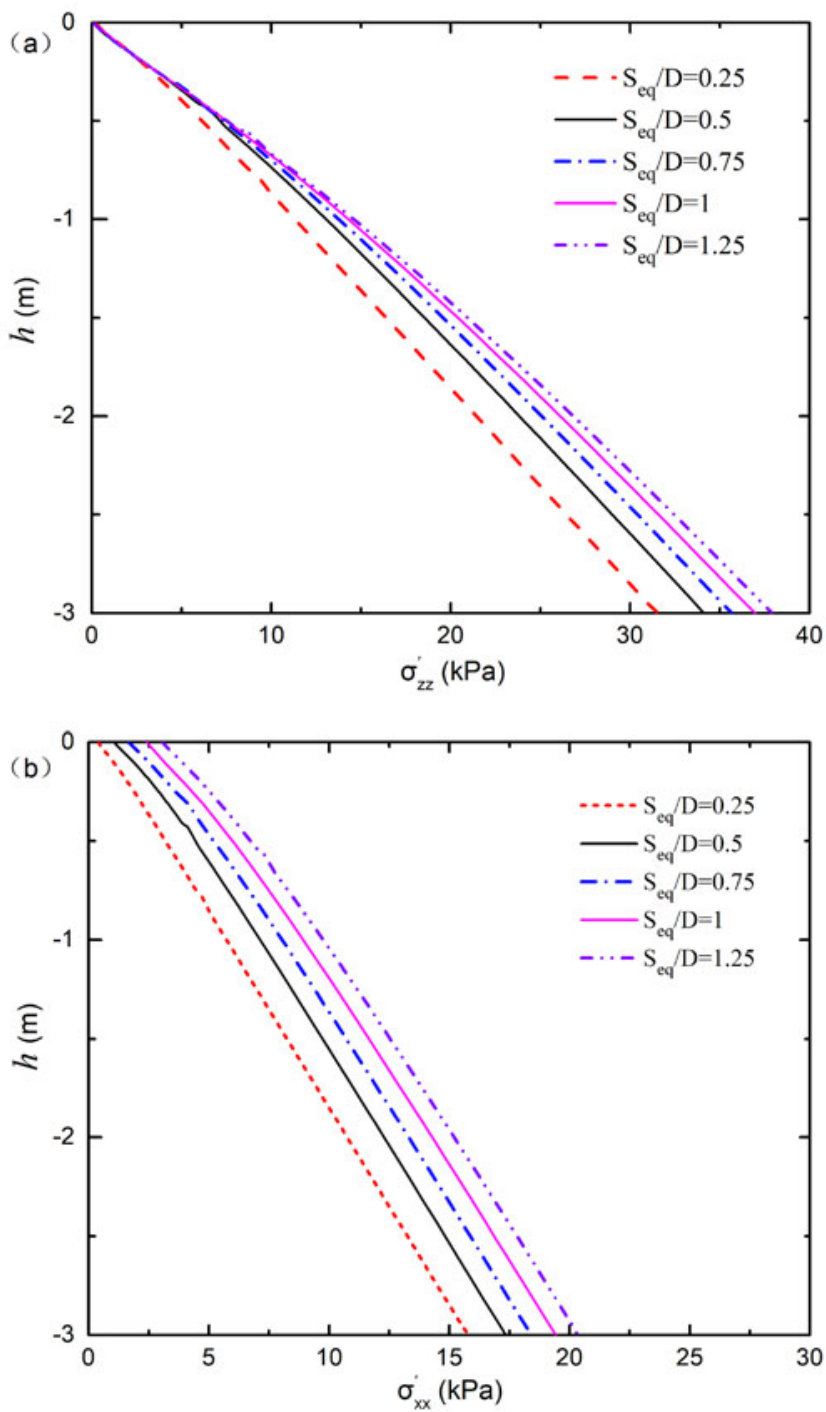

Figure 7. Distributions of the initial effective stress: (a) the vertical effective stress and (b) the horizontal effective stress. the turbulent flow field around the pipeline, further affecting the hydrodynamic pressure acting on the seabed.

Figure 11 demonstrates the vertical distributions of the normalized pore pressure amplitude $\left(\left|\mathrm{u}_{\mathrm{e}}\right| / \sigma_{0}^{\prime}\right)$ under wave troughs beneath the pipeline $(z / h)$, in which $\left|u_{\mathrm{e}}\right|$ is the excess pore pressure amplitude within the seabed, and $\sigma_{0}^{\prime}$ is the initial effective stress, and $\max \left(\left|\mathrm{u}_{\mathrm{e}}\right| / \sigma_{0}^{\prime}\right)$ is used to define the liquefaction potential. As shown in Figure 11, the equilibrium scour depth $\left(S_{e q}\right)$ has a considerable effect on the distributions of the pore pressure and liquefaction depth $\left(h_{l}\right)$. As the scour depths increase, the maximum liquefaction depth and liquefaction potential $\left(\max \left(\left|\mathrm{u}_{\mathrm{e}}\right| / \sigma_{0}^{\prime}\right)\right)$ of the seabed decrease. When the equilibrium scour depth is $0.25 \mathrm{D}$, the maximum liquefaction depth $\left(h_{l}\right)$ of the seabed is $0.21 h$ (i.e., $h_{l}=0.63 D$ ). When the equilibrium scour depth is $0.5 D$, the maximum liquefaction depth is $0.173 h$ (i.e., $h_{l}=0.52 D$ ). The maximum liquefaction depth $\left(h_{l}\right)$ at $S_{e q}=0.5 D$ can decrease by $25.3 \%$ compared to that at $S_{e q}=0.25 D$. When the scour depth reaches $0.75 D$, the excess pore pressure $\left(\left|u_{e}\right|\right)$ is 0.85 times the initial effective stress $\left(\sigma_{0}^{\prime}\right)$, and the seabed no longer liquefies. With the increase in scour depth, $\left|\mathrm{u}_{\mathrm{e}}\right| / \sigma_{0}^{\prime}$ decreases, which means that the anti-liquefaction ability of the seabed under the pipeline increases. A potential reason that might account for this phenomenon is that the initial effective stress and the turbulent flow field around the pipeline are highly relevant to the scour depth. On the one hand, the variations in the scour depths influence the wave pressure acting on the seabed and the pore pressure distribution within the seabed. On the other hand, the increases in scour depth could increase the initial effective stress in the soil surrounding the pipeline and enhance the anti-liquefaction ability of the seabed. As shown in Figures 7 and 8, the increase in the initial effective stress is obviously greater than the pore pressure caused by the change in the turbulent flow field. Therefore, the anti-liquefaction ability of the seabed is enhanced with increasing scour depth.

\subsection{Effects of seabed characteristics}

The soil properties are key influencing factors that determine the liquefaction depth of the seabed. Among those soil properties, the permeability coefficient $\left(k_{s}\right)$ and the degree of saturation $\left(S_{r}\right)$ have important effects on the distribution of the wave-induced pore pressure. The soil permeability directly determines how rapidly pore fluid is transmitted between porous mediums. Previous studies showed that,

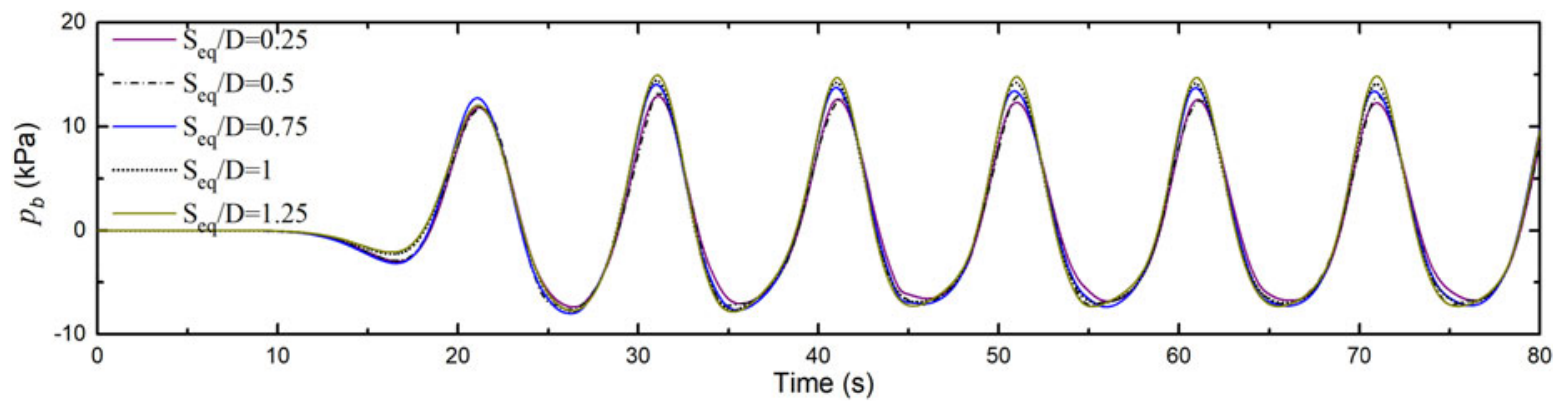

Figure 8. Time series of the wave pressures with different scour depths at points $O_{\mathrm{A}}$. 

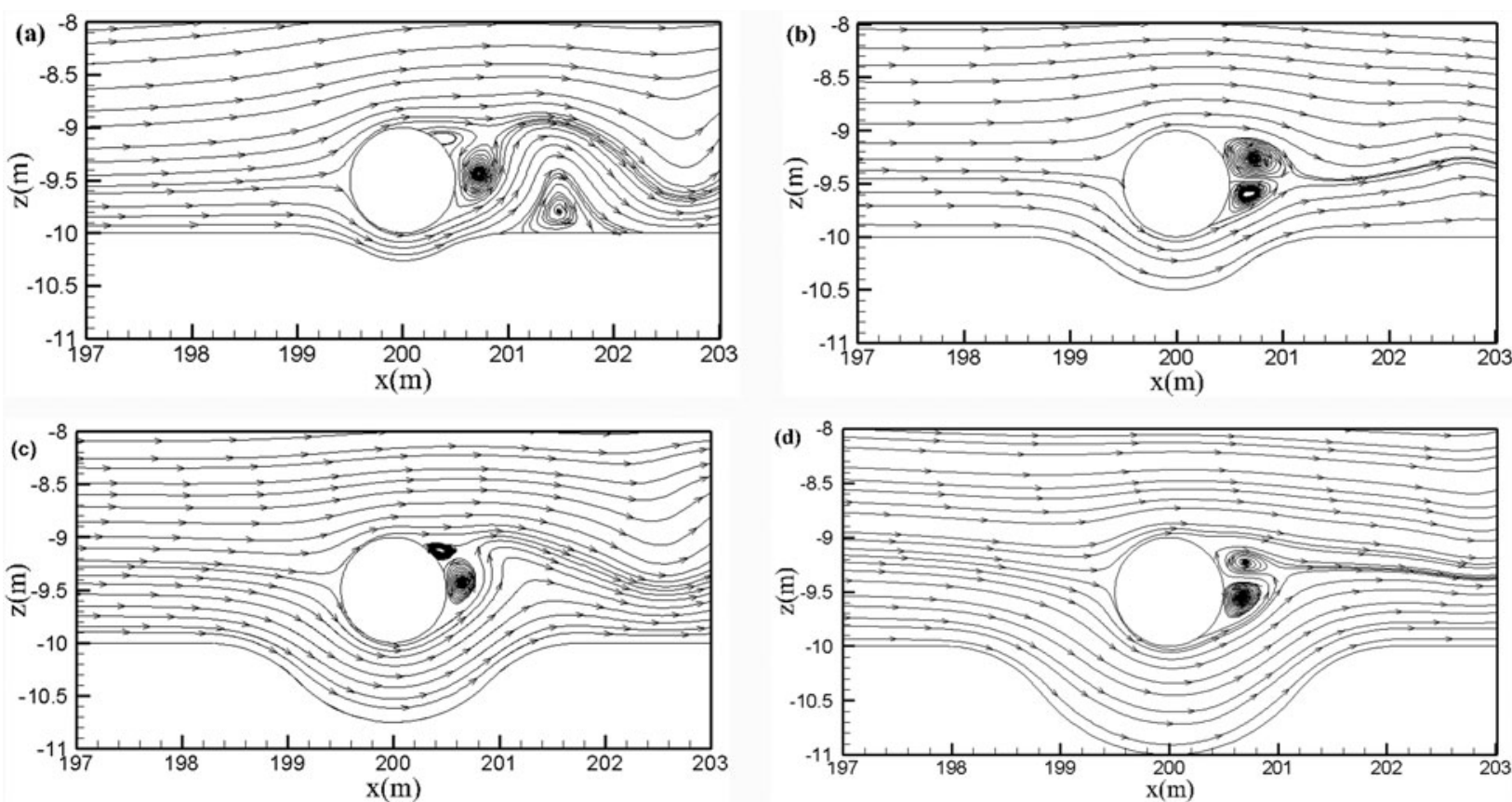

Figure 9. Streamlines at wave troughs according to $S_{e q} / D:(a) S_{e q} / D=0.25$, (b) $S_{e q} / D=0.5$, (c) $S_{e q} / D=0.75$ and (d) $S_{e q} / D=1$.
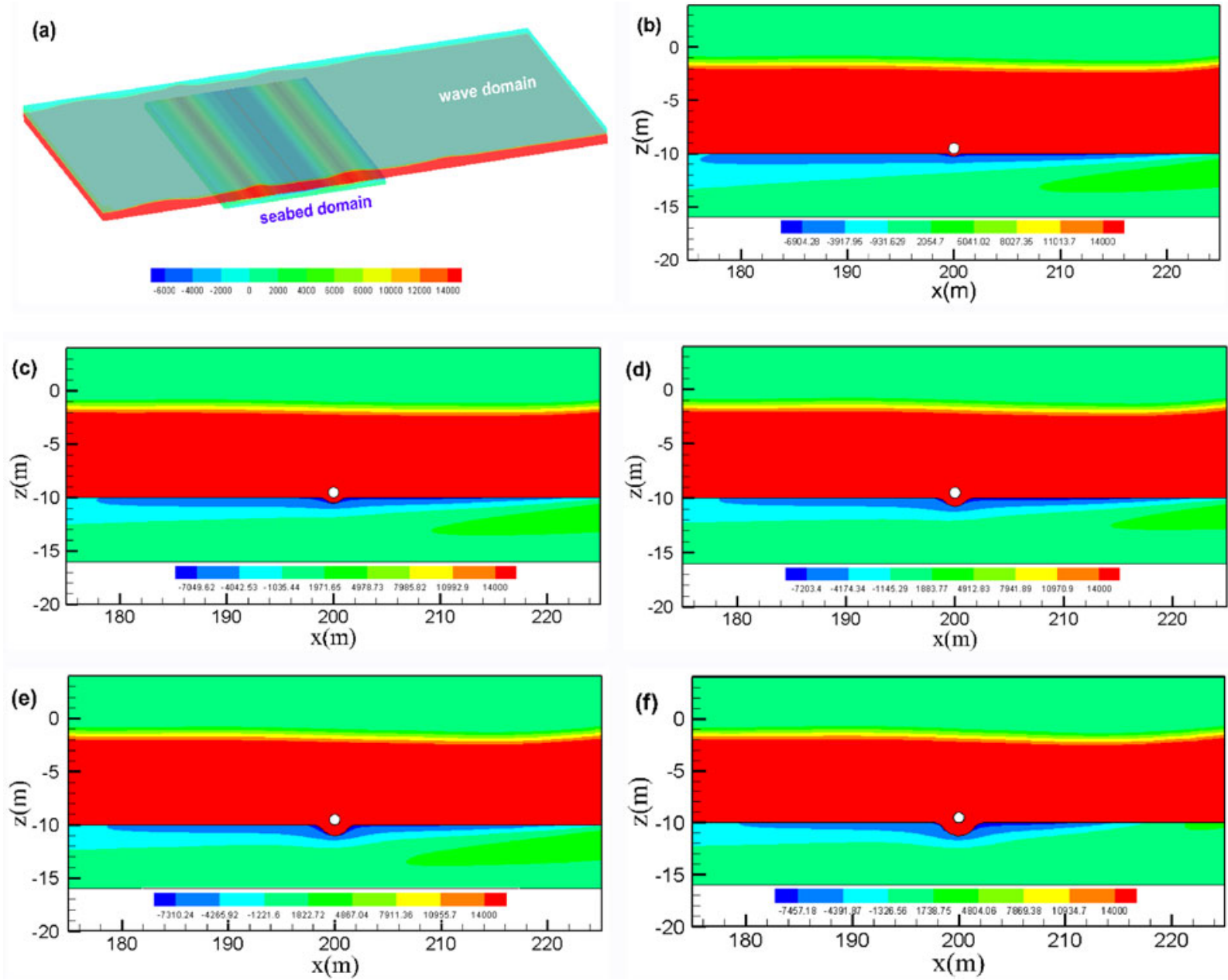

Figure 10. Contours of wave-induced pore pressure within the seabed for various scour depths: (a) the three-dimensional view, (b) $S_{e q} / D=0.25,(c) S_{e q} / D=0.5$, (d) $S_{e q} / D=0.75$, (e) $S_{e q} / D=1$ and (f) $S_{e q} / D=1.25$. 


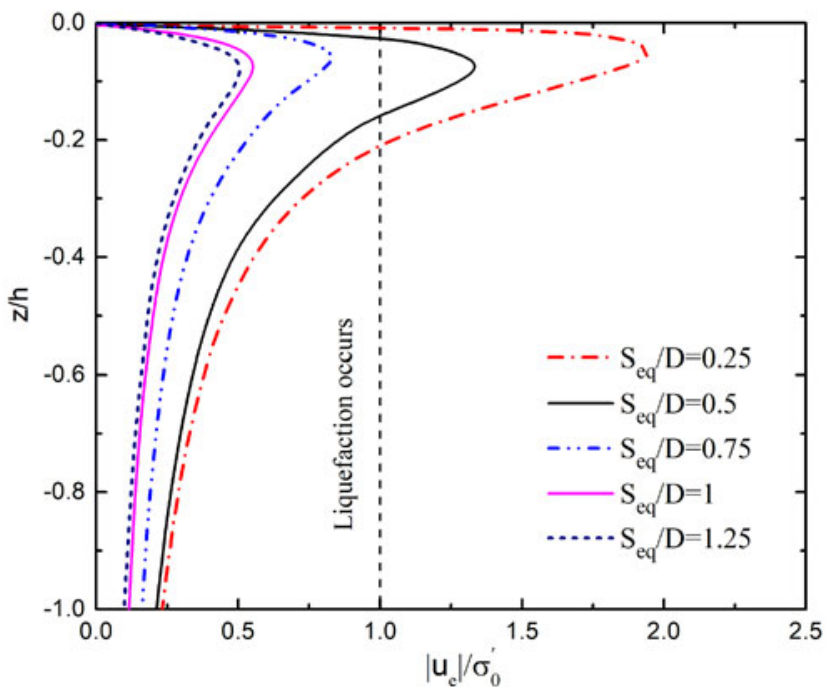

Figure 11. Vertical distributions of the normalized pore pressure amplitude beneath the pipeline for various scour depths.
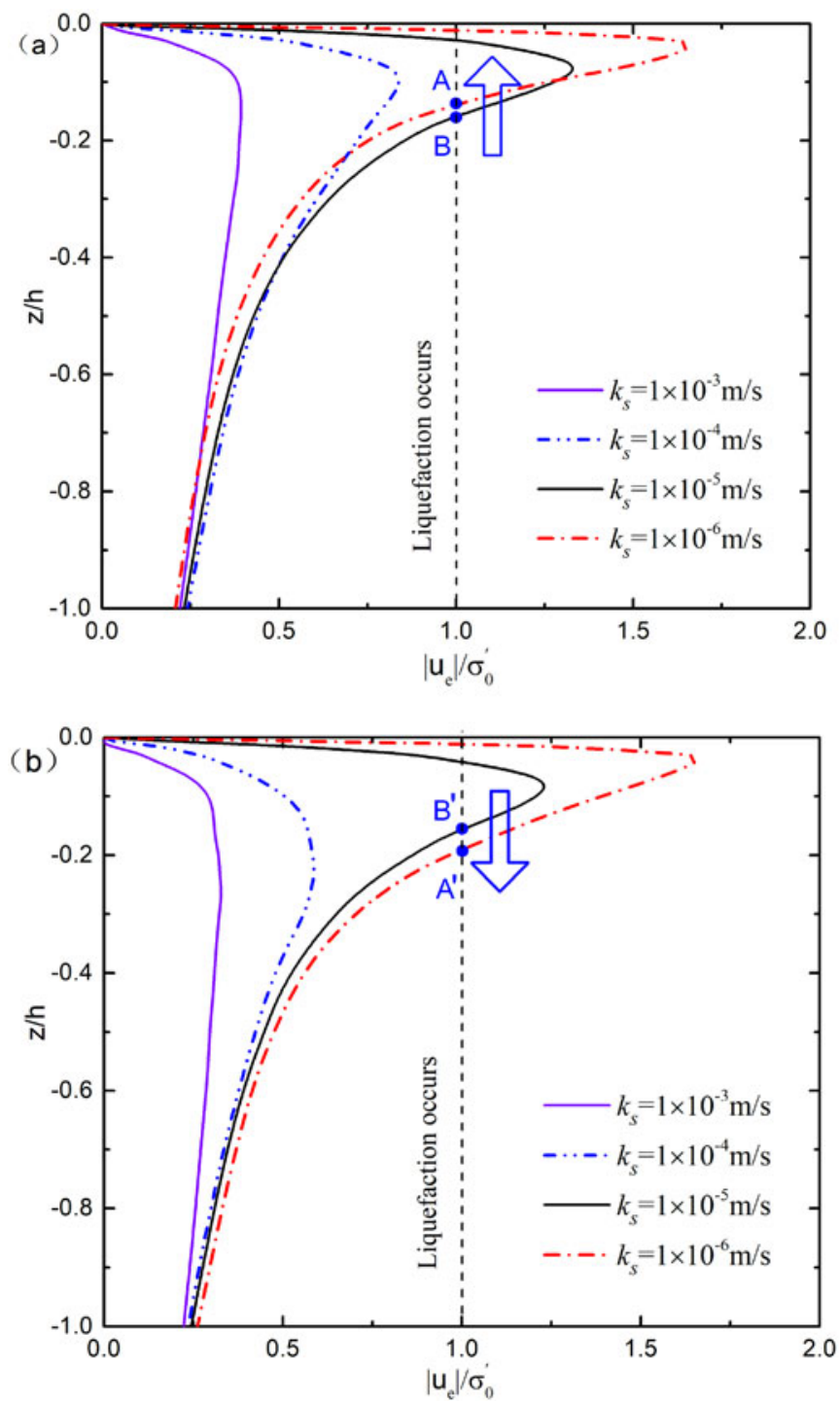

Figure 12. Vertical distributions of the normalized pore pressure amplitude beneath the pipeline for different permeability coefficients $\left(k_{s}\right)$ : (a) anisotropic solutions and (b) isotropic solutions.

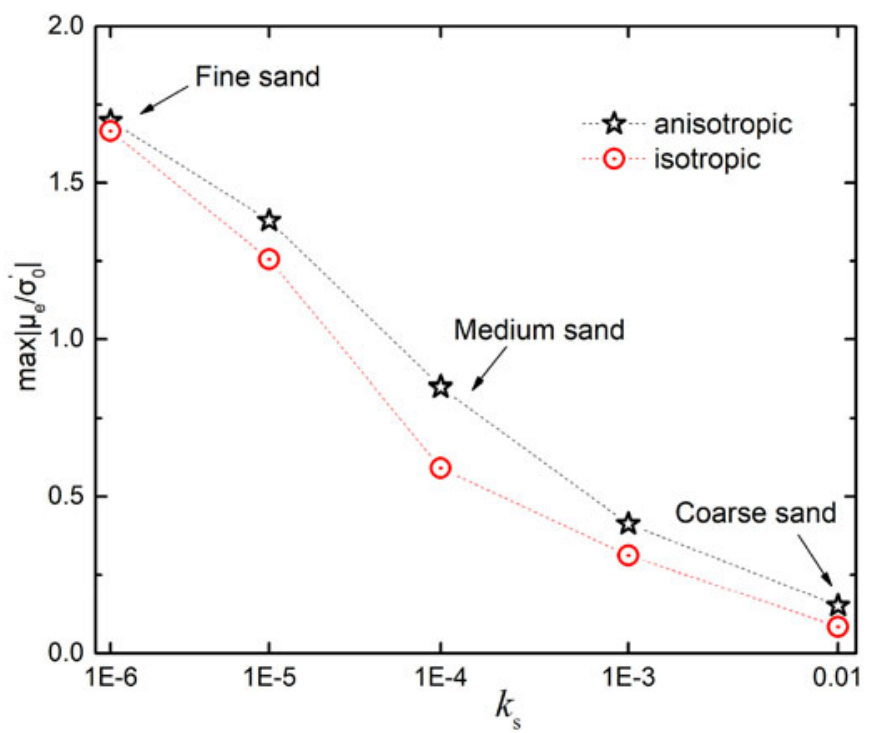

Figure 13. Distributions of the liquefaction potential with different permeability $\left(k_{s}\right)$ for both isotropic and anisotropic solutions.

under isotropic conditions, the seabed with lower permeability is easier to liquefy. Similarly, the degree of saturation affects the pore pressure transmission behavior within the seabed due to different air contents (Tørum 2007; Michallet, Mory, and Piedra-Cueva 2009). Here, to explore the influence of soil properties on the seabed response, four grades of degree of saturation $\left(S_{r}=0.96,0.97,0.98\right.$ and 0.99$)$ and permeability coefficients $\left(k_{s}=k_{z}=1.0 \times 10^{-3} \mathrm{~m} / \mathrm{s}, 1.0 \times\right.$ $10^{-4} \mathrm{~m} / \mathrm{s}, 1.0 \times 10^{-5} \mathrm{~m} / \mathrm{s}$ and $1.0 \times 10^{-6} \mathrm{~m} / \mathrm{s}$ ) are adopted in the simulation. The horizontal permeability is equal to five times the vertical permeability, i.e., $k_{x}=k_{y}=5 k_{z}=5 k_{s}$, according to the work of Maasland (1957). The equilibrium scour depth $\left(S_{e q}\right)$ is $0.5 D$.

Figure 12 gives the vertical distribution of the normalized pore pressure amplitude beneath the pipeline with different permeability coefficients $\left(k_{s}\right)$. It is shown that with the decrease in the seabed permeability coefficients, the soil liquefaction potential $\left(\max \left(\mathrm{u}_{\mathrm{e}} / / \sigma_{0}^{\prime}\right)\right)$ has a noticeable increase. In the meantime, the vertical ordinate of $\max \left(\left|\mathrm{u}_{\mathrm{e}}\right| / \sigma_{0}^{\prime}\right)$ has a slight increase, which means that potential liquefaction zones tend to develop on the surface of the seabed. For isotropic seabeds, i.e., $k_{s}=k_{z}=k_{x}=k_{y}$, previous research indicates that decreasing the permeability coefficient can increase the soil liquefaction depth with isotropic solutions (Zhou, Zhang, and Yan 2014; Duan, Liao, et al. 2017). This agrees with the results of Figure 12(b). However, under anisotropic conditions, it is noteworthy that the maximum liquefaction depth (A) at $k_{s}=1.0 \times 10^{-6} \mathrm{~m} / \mathrm{s}$ is less than the maximum liquefaction depth (B) at $k_{s}=$ $1.0 \times 10^{-5} \mathrm{~m} / \mathrm{s}$ (Figure 12(a)). This is because the horizontal permeability is larger than the vertical permeability under anisotropic conditions. When there is higher pore pressure within the seabed, the flow velocity in the horizontal direction is greater than that in the vertical direction. The pore pressure is harder to transmit in the vertical direction, which causes the liquefaction depth to become shallow. This means that when the permeability coefficient is small, the 


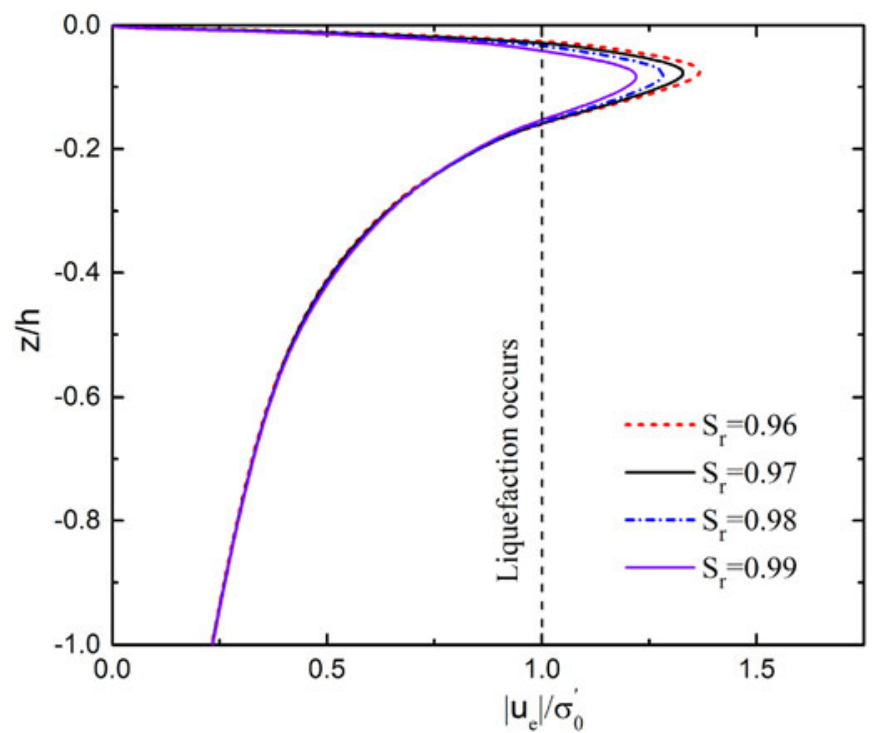

Figure 14. Vertical distributions of the normalized pore pressure amplitude below the pipeline for different degrees of saturation $\left(S_{r}\right)$.

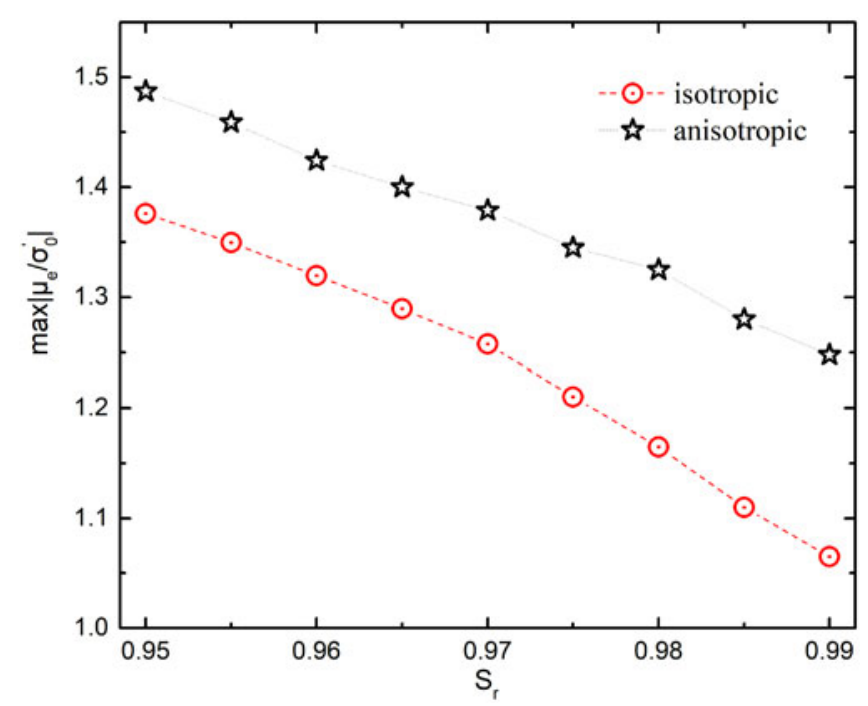

Figure 15. Distributions of the liquefaction potential with different degrees of saturation $\left(S_{r}\right)$ for both isotropic and anisotropic solutions.

pore pressure amplitude may also decrease in the lower part of the seabed, which is consistent with the results of Figure 12(a).

It is of interest to study the differences in the liquefaction potential beneath the pipeline between anisotropic and isotropic soil behavior. Figure 13 shows the variation in the liquefaction potential $\left(\max \left(\left|\mathrm{u}_{\mathrm{e}}\right| / \sigma_{0}^{\prime}\right)\right)$ with different permeability coefficients. The relative differences in the liquefaction potential between anisotropic and isotropic solutions become more significant as the permeability coefficients $\left(k_{s}\right)$ increase. Compared with isotropic solutions, the liquefaction potential $\left(\max \left(\left|\mathrm{u}_{\mathrm{e}}\right| / \sigma_{0}^{\prime}\right)\right)$ increases $3 \%$ in fine sand, increases $46 \%$ in medium sand and increases $72 \%$ in coarse sand under anisotropic solutions. This is because the pore fluid is more difficult to move between the fine sand solids due to the low permeability. Therefore, liquefaction analysis with anisotropic consideration is recommended for medium sand seabeds and coarse sand seabeds.
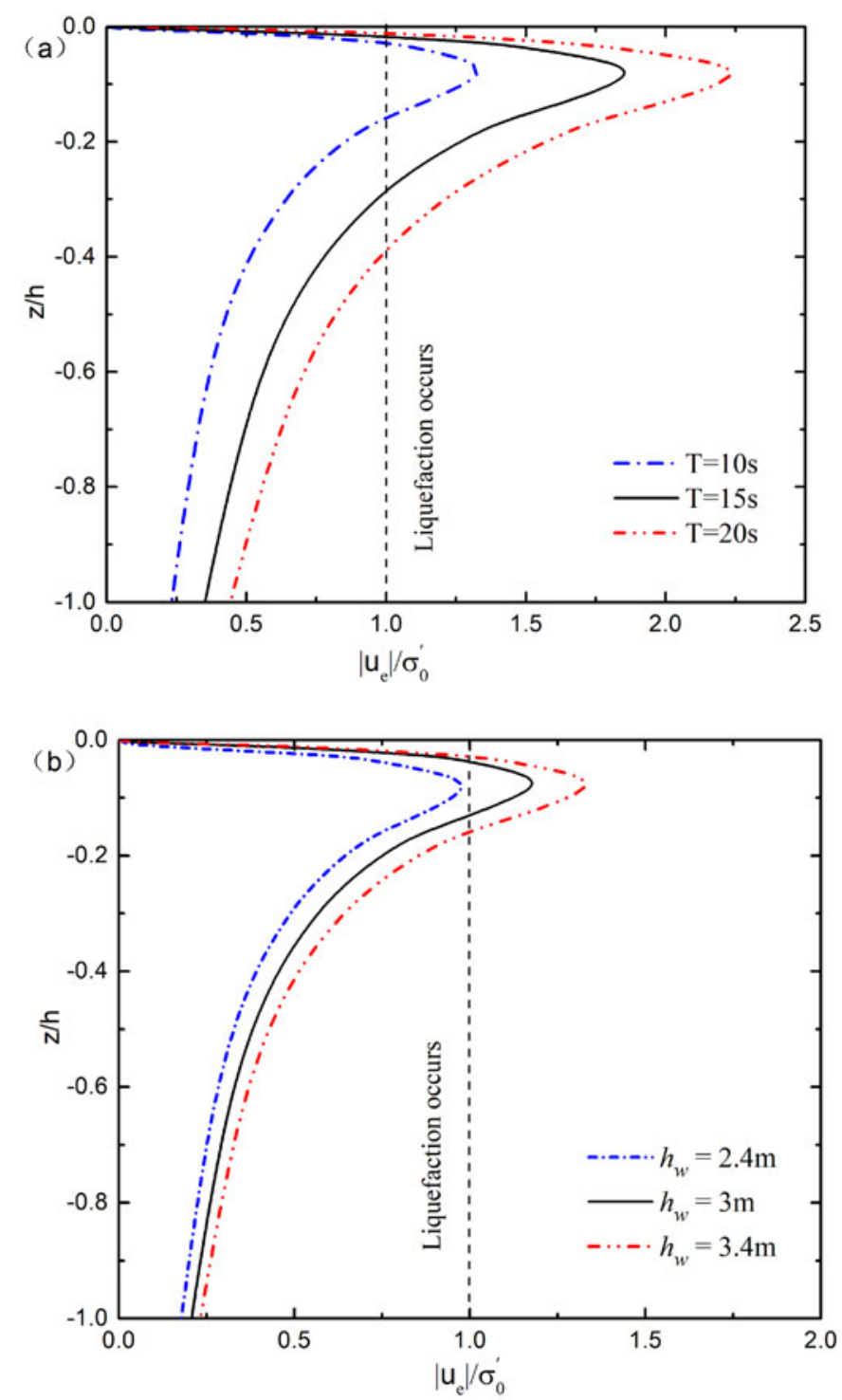

Figure 16. Vertical distributions of the normalized pore pressure amplitude beneath the pipeline for different wave characteristics (a) wave period $(T)$ and (b) wave height $\left(h_{w}\right)$.

The distributions of the normalized pore pressure amplitude along the vertical axis below the pipeline with different degrees of saturation $\left(S_{r}\right)$ are plotted in Figure 14. As shown in Figure 14, the seabed with a smaller degree of saturation can cause a larger liquefaction risk and liquefaction depth.

Figure 15 illustrates the soil liquefaction potential around the pipeline for both isotropic and anisotropic solutions. With increasing saturation $\left(S_{r}\right)$, the soil liquefaction depth and liquefaction potential $\left(\max \left|\mathrm{u}_{\mathrm{e}}\right| / \sigma_{0}^{\prime}\right)$ decrease. This is because the wave-induced upward seepage force within the seabed is greater for smaller saturation $\left(S_{r}\right)$. In addition, the anisotropic seabed is more likely to be liquefied at the same saturation $\left(S_{r}\right)$.

\subsection{Effects of wave characteristics and uniform current}

As mentioned previously, wave characteristics, i.e., wave period and wave height, play an important role in the 


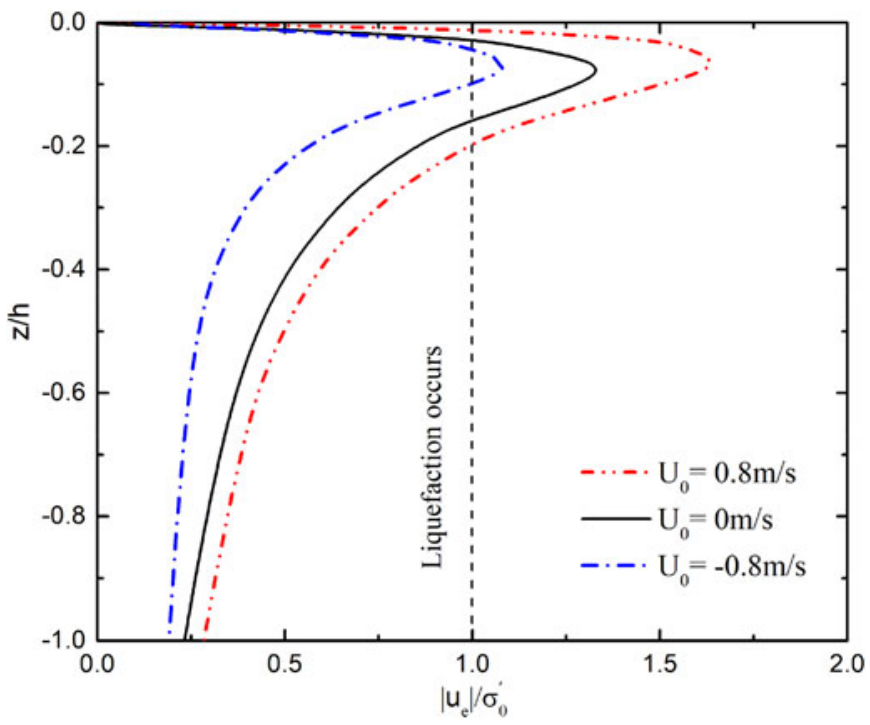

Figure 17. Vertical distribution of the normalized pore-pressure amplitude beneath the pipeline under wave-current interaction.

evaluation of the seabed response and liquefaction depth. In this paper, their effects on the wave-induced seabed response and liquefaction depth are investigated by varying the values of the wave period from $10 \mathrm{~s}$ to $20 \mathrm{~s}$ and the wave height from $2.4 \mathrm{~m}$ to $3.4 \mathrm{~m}$. The equilibrium scour depth $\left(S_{e q}\right)$ is $0.5 \mathrm{D}$. In addition, other parameters remain as constants (see Table 3 ).

Figure 16 gives the vertical distribution of the normalized pore pressure amplitude beneath the pipeline with different wave characteristics. As shown in Figure 16, the liquefaction depth increases with increasing wave period and wave height. This is mainly because the wave with a longer wave period and higher wave height will simultaneously increase the wavelength and carry more energy.

Except for the wave characteristics, the current velocity is another factor that influences the distribution of the pore pressure and liquefaction depth. Thus, the effects of current velocity on the wave-induced oscillatory seabed response need to be investigated. In this section, the following current $\left(U_{0}=0.8 \mathrm{~m} / \mathrm{s}\right)$, without current $\left(U_{0}=0\right)$ and opposing current $\left(U_{0}=-0.8 \mathrm{~m} / \mathrm{s}\right)$ are adopted in the simulation. Figure 17 shows the vertical distribution of the normalized pore pressure amplitude beneath the pipeline under wavecurrent interaction.

It is shown that if the waves propagate on a current, the liquefaction depth within the seabed generally increases and vice versa. This is because waves with a following-current can increase the hydrodynamic pressure acting on the seabed. This means that the liquefaction risk of the seabed increases under waves with a following-current.

\section{Conclusions}

This paper proposed a three-dimensional hybrid model to study the effect of scour depth on wave-induced seabed response and maximum liquefaction depth around a pipeline. The effects of wave characteristics and seabed characteristics on the wave-induced seabed response are also examined. The following conclusions are drawn:

1. Local scour leads to the stress release within the soil around the scour hole, which further affects the initial stress state of the seabed. The vertical stress release is greatly affected by local scour, while the horizontal stress release is relatively less affected. Stress release causes the seabed to liquefy more easily.

2. Scour can significantly affect the turbulent flow field and initial stress field in the soil surrounding the pipeline and then affect the wave-induced pore pressure distribution. The wave-induced maximum liquefaction depth beneath the pipeline noticeably decreases with increasing scour depth, primarily due to the change in the seabed initial stress state.

3. The liquefaction depth and liquefaction potential of the seabed increases with decreases in both the permeability and saturation degree. For the fine seabed in the present study, under anisotropic conditions, the maximum liquefaction depth decreases with the decrease in the permeability coefficients, which is inconsistent with the results of isotropic solution.

4. The liquefaction depth of the seabed increases as the wave height and wave period increase. Compared with the wave alone, the liquefaction risk of the seabed increases under waves with a following-current.

5. Both the equilibrium scour depth $\left(S_{e q}\right)$ and liquefaction depth $\left(h_{l}\right)$ should be taken into account in the safety design of the pipeline. In the present study, when the equilibrium scour depth is $0.5 \mathrm{D}$, the maximum liquefaction depth is $0.52 \mathrm{D}$. Therefore, the liquefaction depth should not be ignored.

\section{Funding}

This work has been supported by the National Science Fund for Distinguished Young Scholars (51625902), the Taishan Scholars Program of Shandong Province (TS201511016) and the Young Elite Scientist Sponsorship Program by Cast (2016QNRC001).

\section{References}

Demirdzic, I., I. Horman, and D. Martinovic. 2000. Finite Volume Analysis of Stress and Deformation in Hygro-Thermo-Elastic Orthotropic Body. Computer Methods in Applied Mechanics and Engineering 190 (8):1221-1232. doi:10.1016/S0045-7825(99)00476-4.

Duan, L., D.-S. Jeng, C. Liao, B. Zhu, and D. Tong. 2017. A ThreeDimensional Poro-Elastic Integrated Model for Wave and CurrentInduced Oscillatory Soil Liquefaction Around an Offshore Pipeline. Applied Ocean Research 68:293-306. doi:10.1016/j.apor.2017.09.009.

Duan, L., C. Liao, D. Jeng, and L. Chen. 2017. 2D Numerical Study of Wave and Current-Induced Oscillatory Non-Cohesive Soil Liquefaction Around a Partially Buried Pipeline in a Trench. Ocean Engineering 135:39-51. doi:10.1016/j.oceaneng.2017.02.036.

Fredsøe, J. 2016. Pipeline-Seabed Interaction. Journal of Waterway, Port, Coastal, and Ocean Engineering 142 (6):03116002. doi:10.1061/ (ASCE)WW.1943-5460.0000352.

Fredsøe, J., B. M. Sumer, and M. M. Arnskov. 1992. Time Scale for Wave/Current Scour Below Pipelines. In The First International 
Offshore and Polar Engineering Conference. Edinburgh, UK: International Society of Offshore and Polar Engineering.

Gao, F. P., N. Wang, and J. Li. 2016. Pipe-Soil Interaction Model for Current-Induced Pipeline Instability on a Sloping Sandy Seabed. Canadian Geotechnical Journal 53 (11):1822-1830. doi:10.1139/cgj2016-0071.

Gao, F. P., B. Yang, Y. X. Wu, and S. M. Yan. 2006. Steady Current Induced Seabed Scour Around a Vibrating Pipeline. Applied Ocean Research 28 (5):291-298. doi:10.1016/j.apor.2007.01.004.

Gonzalez-Juez, E., E. Meiburg, T. Tokyay, and G. Constantinescu. 2010. Gravity Current Flow Past a Circular Cylinder: Forces, Wall Shear Stresses and Implications for Scour. Journal of Fluid Mechanics 649:69-102. doi:10.1017/S002211200999334X.

Higuera, P., J. L. Lara, and I. J. Losada. 2013. Realistic Wave Generation and Active Wave Absorption for Navierstokes Models: Application to Openfoam. Coastal Engineering 71:102-118. doi:10. 1016/j.coastaleng.2012.07.002.

Huang, Y., Y. Bao, M. Zhang, C. Liu, and P. Lu. 2015. Analysis of the Mechanism of Seabed Liquefaction Induced by Waves and Related Seabed Protection. Natural Hazards 79 (2):1399-1408. doi:10.1007/ s11069-015-1897-1.

Jeng, D. S. 1997. Wave-Induced Seabed Instability in Front of a Breakwater. Ocean Engineering 24 (10):887-917. doi:10.1016/S00298018(96)00046-7.

Jeng, D. S., M. Rahman, and T. Lee. 1999. Effects of Inertia Forces on Wave-Induced Seabed Response. International Journal of Offshore and Polar Engineering 9 (4):307-313.

Jeng, D. S. 2012. Porous Models for Wave-Seabed Interactions. Heidelberg: Springer.

Jung, J. H., H. S. Yoon, and J. Oceaneng. 2016. Effect of Scour Depth on Flow Around Circular Cylinder in Gravity Current. Ocean Engineering 117:78-87. doi:10.1016/j.oceaneng.2016.03.025.

Jacobsen, N. G., D. R. Fuhrman, and J. Fredsøe. 2012. A Wave Generation Toolbox for the Open-Source CFD Library: OpenFoam ${ }^{\circledR}$. International Journal for Numerical Methods in Fluids 70 (9):1073-1088. doi:10.1002/fld.2726.

Li, Y., M. C. Ong, and T. Tang. 2018. Numerical Analysis of WaveInduced Poro-Elastic Seabed Response Around a Hexagonal Gravity-Based Offshore Foundation. Coastal Engineering 136:81-95. doi:10.1016/j.coastaleng.2018.02.005.

Lin, Z., D. Pokrajac, Y. Guo, D-S Jeng, T. Tang, N. Rey, J. Zheng, and J. Zhang. 2017. Investigation of Nonlinear Wave-Induced Seabed Response Around Mono-Pile Foundation. Coastal Engineering 121: 197-211. doi:10.1016/j.coastaleng.2017.01.002.

Liu, B., D. S. Jeng, G. L. Ye, and B. Yang. 2015. Laboratory Study for Pore Pressures in Sandy Deposit Under Wave Loading. Ocean Engineering 106:207-219. doi:10.1016/j.oceaneng.2015.06.029.

Maasland, M. 1957. Soil Anisotropy and Land Drainage. In Drainage of Agricultural Lands, Vol. 7, 216-285. Madison, WI: ASA.

Mao, Y. 1986. The Interaction Between a Pipeline and an Erodible Bed. PhD. thesis, Technical University of Denmark, Lyngby, Denmark.

Mattioli, M., J. M. Alsina, A. Mancinelli, M. Miozzi, and M. Brocchini. 2012. Experimental Investigation of the Nearbed Dynamics Around a Submarine Pipeline Laying on Different Types of Seabed: The Interaction Between Turbulent Structures and Particles. Advances in Water Resources 48:31-46. doi:10.1016/j.advwatres.2012.04.010.

Mattioli, M., A. Mancinelli, and M. Brocchini. 2013. Experimental Investigation of the Wave-Induced Flow Around a SurfaceTouching Cylinder. Journal of Fluids and Structures 37:62-87. doi: 10.1016/j.jfluidstructs.2012.10.002.
Michallet, H., M. Mory, and I. Piedra-Cueva. 2009. Wave-Induced Pore Pressure Measurements Near a Coastal Structure. Journal of Geophysical Research Oceans 114 (C6):C06019. doi:10.1029/ 2008JC005071.

Qi, W. G., and F. P. Gao. 2014. Physical Modeling of Local Scour Development Around a Large-Diameter Monopile in Combined Waves and Current. Coastal Engineering 83:72-81. doi:10.1016/j. coastaleng.2013.10.007.

Sumer, B. M., and J. Fredsøe. 1990. Scour Below Pipelines in Waves. Journal of Waterway, Port, Coastal, and Ocean Engineering 116 (3): 307-323. doi:10.1061/(ASCE)0733-950X(1990)116:3(307).

Sumer, B. M., and J. Fredsøe. 2002. The Mechanics of Scour in the Marine Environment. Singapore: World Scientific.

Sumer, B. M., Y. Mao, and E. J. Freds. 1988. Interaction Between Vibrating Pipe and Erodible Bed. Journal of Waterway, Port, Coastal, and Ocean Engineering 114 (1):81-92. doi:10.1061/ (ASCE)0733-950X(1988)114:1(81).

Sumer, B. M., and B. Mutlu. 2014. Flow-Structure-Seabed Interactions in Coastal and Marine Environments. Journal of Hydraulic Research 52 (1):1-13. doi:10.1080/00221686.2014.881927.

Sumer, B. M., C. Truelsen, T. Sichmann, and J. Fredsøe. 2001. Onset of Scour Below Pipelines and Self-Burial. Coastal Engineering 42 (4) 313-335. doi:10.1016/S0378-3839(00)00066-1.

Tørum, A. 2007. Wave-Induced Pore Pressures-Air/Gas Content. Journal of Waterway, Port, Coastal, and Ocean Engineering 133 (1): 83-86. doi:10.1061/(ASCE)0733-950X(2007)133:1(83).

Tsui, Y., and Helfrich, S. C. 1983. Wave induced pore pressures in submerged sand layer. Journal of Geotechnical Engineering 109:4(603). doi:10.1061/(ASCE)0733-9410(1983)109:4(603).

Turcotte, B. R., F. H. Kulhawy, and P. L. Liu. 1984. Laboratory Evaluation of Wave Tank Parameters for Wave-Sediment Interaction School of Civil and Environmental Engineering. New York: Cornell University.

Veritas, D. N. 2010. On-Bottom Stability Design of Submarine Pipelines, DNV Recommended Practice DNV-RP-F109, Oslo, Norway.

Wilcox, D. C. 1998. Turbulence Modeling for CFD. La Canada, CA: DCW Industries.

Wu, Y., and Y. M. Chiew. 2012. Three-Dimensional Scour at Submarine Pipelines. Journal of Hydraulic Engineering 138 (9): 788-795. doi:10.1061/(ASCE)HY.1943-7900.0000583.

Yamamoto, T., H. Koning, H. Sellmeijer, and E. V. Hijum. 1978. On the Response of a Poroelastic Bed to Water Waves. Journal of Fluid Mechanics 87 (1):193-206. doi:10.1017/S0022112078003006.

Zen, K., and H. Yamazaki. 1990. Mechanism of Wave-Induced Liquefaction and Densification in Seabed. Soils and Foundations 30 (4):90-104. doi:10.3208/sandf1972.30.4_90.

Zhang, M., Y. Huang, and Y. Bao. 2016. The Mechanism of Shallow Submarine Landslides Triggered by Storm Surge. Natural Hazards 81 (2):1373-1383. doi:10.1007/s11069-015-2112-0.

Zhang, M., W. Zhang, Y. Huang, Y. Cai, and S. Shen. 2019. Failure Mechanism of Submarine Slopes Based on the Wave Flume Test. Natural Hazards 96 (3):1249-1262. doi:10.1007/s11069-019-03608-1.

Zhou, X.-L., J. Zhang, J.-H. Wang, Y.-F. Xu, and D.-S. Jeng. 2014. Stability and Liquefaction Analysis of Porous Seabed Subjected to Cnoidal Wave. Applied Ocean Research 48:250-265. doi:10.1016/j. apor.2014.09.005

Zhou, X.-L., J. Zhang, and Y. Yan. 2014. Wave-Induced Response of Submarine Pipeline Embedded in Porous Seabed. In Geo-Shanghai International Conference, Shanghai. 